\title{
ATIVIDADE ANTINOCICEPTIVA DE POLISSACARÍDEOS ISOLADOS DE FUNGOS DO SEMIÁRIDO BAIANO
}

\author{
Daniela da Silva Borges ${ }^{1}$; Flávia Oliveira de Lima²; Bruno Cerqueira da Silva ${ }^{3}$; Sandra \\ Aparecida de Assis ${ }^{4}$ \\ 1. Bolsista FAPESB, Graduanda em Farmácia, Universidade Estadual de Feira de Santana, e-mail: \\ danielaborges856@gmail.com \\ 2. Orientadora, Departamento de Saúde, Universidade Estadual de Feira de Santana, e- \\ mail:flavia_lima2000@yahoo.com.br \\ 3. Colaborador, Departamento de Saúde, Universidade Estadual de Feira de Santana, e-mail: \\ farma.bruno@yahoo.com.br \\ 4. Colaborador, Departamento de Saúde, Universidade Estadual de Feira de Santana, e- \\ mail:sandrinhaassis@yahoo.com.br
}

PALAVRAS-CHAVE: dor, antinocicepção, semiárido.

\section{INTRODUÇÃO}

A dor é conceituada como uma experiência sensorial e emocional desagradável e descrita em termos de lesões teciduais reais ou potenciais (KRELING; CRUZ; PIMENTA, 2006). Embora uma pessoa consiga sobreviver com dor, ela interfere no seu bem-estar, nas relações sociais e familiares, no desempenho do seu trabalho, influenciando assim a sua qualidade de vida (RIGOTTI; FERREIRA, 2005). Mediante a prevalência da dor, muitas pesquisas buscam novas opções terapêuticas para o seu controle, em virtude das limitações do tratamento convencional, tais como: efeitos adversos, pacientes refratários à terapia e a não responsividade ao tratamento em alguns casos.

Embora sejam altamente eficazes, os analgésicos de ação central geralmente não estão dissociados de efeitos adversos importantes. Adicionalmente, os analgésicos de ação periférica também apresentam efeitos indesejáveis, tais como lesões do trato gastrointestinal e renal (RANG et al., 2012). Assim, tem-se a necessidade de buscar medidas alternativas para o desenvolvimento de medicamentos para o combate da dor. Logo, a busca por novos analgésicos é uma prática necessária e relevante, o que justifica a realização deste trabalho.

Desde a descoberta da penicilina por Fleming em 1928, surgiram vários fármacos importantes baseados em metabólitos de fungos. Sendo assim, há uma forte tendência em se explorar comercialmente a biomassa de fungos e leveduras, já que estes microorganismos são uma fonte abundante de polissacarídeos que possuem reconhecida atividade biológica. Dentre estes polissacarídeos encontrados na parede celular de fungos, destacam-se as glucanas, que são polímeros de glicose vastamente distribuídos na natureza e classificados de acordo com o tipo de ligação glicosídica - $\alpha, \beta$ - da cadeia principal (SILVA et al., 2006).

Assim, o objetivo deste trabalho é investigar pela primeira vez o efeito do tratamento com polissacarídeos isolados dos fungos Periconia byssoides, Torula herbarum e Moorella speciosa em modelos de contorção abdominal induzida pelo ácido acético.

\section{MATERIAIS E MÉTODOS}

\section{Obtenção do polissacarídeo}


Os polissacarídeos de Periconia byssoides, Torula herbarum e Moorella speciosa obtidos a partir da coleção de cultura de Microrganismos da Bahia (CCMB, Feira de Santana, Brasil), foram purificados e caracterizados pelo grupo de pesquisa da $\operatorname{Prof}^{a} \operatorname{Dr}^{a}$ Sandra Aparecida de Assis. Para caracterizar os polissacarídeos produzidos foram utilizadas as técnicas de Espectrometria de Infravermelho (FT-IR) e a Ressonância Magnética Nuclear (RMN).

\section{Animais}

Os experimentos foram realizados com camundongos machos da linhagem Swiss Webster (20-30g) criados no biotério da Universidade Estadual de Feira de Santana. Os animais foram colocados em caixas apropriadas e mantidos nas dependências do biotério, sob temperatura de $22^{\circ} \mathrm{C} \pm 2{ }^{\circ} \mathrm{C}$ e ciclos claro escuro de 12 horas, com livre acesso a ração e água. Todos os experimentos estão de acordo com o protocolo da Associação Internacional para o Estudo da Dor (IASP) para uso de animais de laboratório (ZIMMERMANN, 1983).

\section{Modelo de contorções abdominais induzidas pelo ácido acético}

O teste de contorções abdominais induzidas pela administração intraperitoneal de ácido acético $0,8 \%(0,1 \mathrm{ml} / 10 \mathrm{~g}$ de peso) foi avaliado em camundongos (COLLIER et al., 1968). Os animais foram tratados por via intraperitoneal com os polissacarídeos isolados dos fungos Periconia byssoides, Torula herbarum e Moorella speciosa na dose de $27 \mathrm{mg} / \mathrm{kg}$ ou veículo (grupo controle negativo), 30 minutos antes da administração via intraperitoneal do ácido acético $0,8 \%$. A morfina (grupo controle positivo) foi administrada por via subcutânea na dose de $5 \mathrm{mg} / \mathrm{kg} 40$ minutos antes da administração do ácido acético. A reação observada foi a rotação do corpo com extensão das patas traseiras, caracterizando a contorção abdominal. A intensidade de nocicepção foi quantificada com número de contorções abdominais durante os 30 minutos seguintes ao estímulo. Durante o tempo de observação os animais foram mantidos em cilindros de vidro com diâmetro de $22 \mathrm{~cm}$.

\section{Análise estatística}

Os resultados estão representados como média \pm EPM de 6 animais por grupo, sendo os grupos experimentais comparados pelo teste one-way ANOVA, seguido do teste Bonferroni. O nível de significância será de $\mathrm{p}<0,05$.

\section{RESULTADOS E DISCUSSÃO}

O modelo de contorções abdominais em camundongo é uma ferramenta de triagem para a avaliação das propriedades analgésicas ou anti-inflamatória de novos agentes (COLLIER et al., 1968). Assim, utilizamos este método para avaliar a atividade biológica dos polissacarídeos isolados de Periconia byssoides, Torula herbarum e Moorella speciosa.

Os resultados obtidos por meio do teste demonstraram que os polissacarídeos Torula herbarum e Moorella speciosa na dose de $27 \mathrm{mg} / \mathrm{kg}$ apresentaram efeito antinociceptivo, sendo o mais acentuado com Torula herbarum. Entretanto, no tratamento com o polissacarídeo isolado do fungo Periconia byssoides com a mesma dose, observamos que não houve inibição no número de contorções abdominais induzidas pelo ácido acético (Figura 1). 


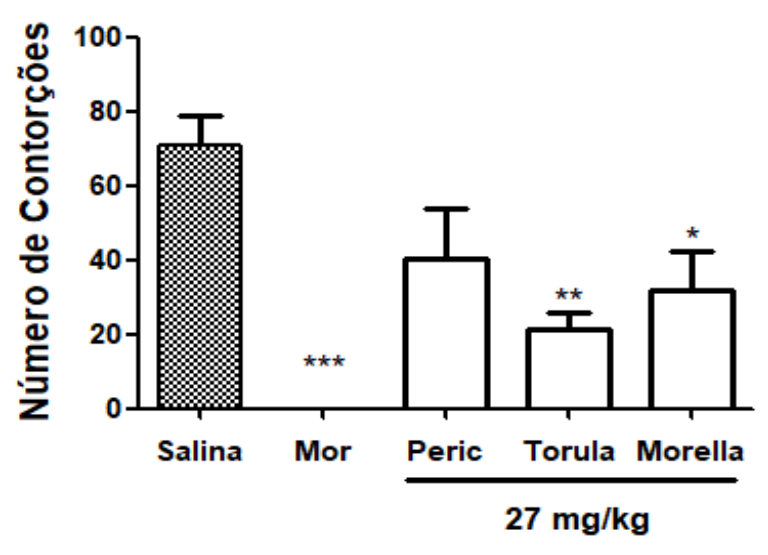

Figura 1: Efeito do tratamento do polissacarídeo Periconia byssoides, Torula herbarum e Moorella speciosa no número de contorções abdominais induzidas pela injeção de ácido acético em camundongos. Os camundongos foram tratados com os polissacarídeo Periconia byssoides, Torula herbarum e Moorella speciosa na dose de $27 \mathrm{mg} / \mathrm{kg}$ ou salina (grupo controle negativo) por via intraperitoneal 30 minutos antes da injeção de ácido acético $0,8 \%$. Morfina (MOR $5 \mathrm{mg} / \mathrm{kg}$ ) foi utilizada como controle positivo, sendo administrada via subcutânea 40 minutos antes do estímulo nociceptivo. Dados estão expressos como média \pm E.P.M.; $n=6$ camundongos por grupo. * Significância estatística em relação ao grupo negativo $(\mathrm{p}<0,05)$, como determinado pelo teste de ANOVA de uma via, seguido pelo teste de Bonferroni.

O efeito algésico do ácido acético ocorre devido uma reação inflamatória aguda relacionada com liberação de mediadores presentes em processos inflamatórios como as prostaglandinas, leucotrienos, histamina, serotonina, bradicinina e eicosanoides (VERMA et al., 2005; BAHAMONDE et al., 2013), resultando em aumento da síntese de ciclooxigenases (COOX), lipooxigenase (LOX) e prostaglandinas (RADU et al., 2013). Isso faz este modelo sensível às substâncias analgésicas de ação central e/ou periférica com os mais variados mecanismos de ação (PERAZA et al., 2007).

Além disso, a ação do ácido acético sobre macrófagos e basófilos, existentes na cavidade abdominal, induz liberação de citocinas, como IL- 8 , IL-1 $\beta$ e TNF- $\alpha$, que estimulam neurônios aferentes primários, aumentando a liberação de aspartato e glutamato no fluido cérebro-espinhal e, juntamente com os outros mediadores, pode induzir a reação nociceptiva característica observada nesse modelo (FENG et al., 2003). O ácido acético desencadeia ainda vasodilatação e permeabilidade vascular (PARVEEN et al., 2007).

A utilização de modelos experimentais como o de contorção abdominal induzida por ácido acético é de fundamental importância para a descoberta de novos fármacos, particularmente de analgésicos, visto que estes só podem ser comercializados após a realização de ensaios farmacológicos pré-clínicos que atestem sua eficácia e segurança.

\section{CONCLUSÃO}

De acordo com os resultados obtidos, o polissacarídeo isolado do fungo Periconia byssoides não apresentou atividade antinociceptiva, por outro lado, o estudo com os glicanos dos fungos Torula herbarum e Moorella speciosa sugere que ambos possuem propriedades antinociceptivas. Entretanto, é necessária a realização de outros testes para a elucidação da estrutura química e para confirmação do efeito antinociceptivo dos glicanos isolados dos fungos Torula herbarum e Moorella speciosa. 


\section{REFERÊNCIAS}

BAHAMONDE, S. M. A. et al. Antinociceptive and anti-inflammatory activities of an aqueous extract of Chiliotrichum diffusum. Revista Brasileira de Farmacognosia, v. 23, n. 4, p. 699-705, 2013.

FENG, Y.I. et al. Gabapentin markedly reduces acetic acid-induced visceral nociception. Anesthesiology, v. 98, n. 3, p. 729-733, 2003.

KRELING, M. C. G. D.; DA CRUZ, D. DE A. L. M.; PIMENTA, C. A. DE M. Prevalência de dor crônica em adultos. Rev Bras Enferm, v. 59, n. 4, p. 509-513, 2006.

PARVEEN, Z. et al. Antiinflammatory and analgesic activities of Thesium chinense Turcz extracts and its major flavonoids, kaampferol and kaempferol-3-Oglucoside. Yakugaku Zasshi, v. 127, n. 8, p. 1275-1279, 2007.

PERAZA, G. G. et al. O uso de modelos animais para avaliar o potencial antinociceptivo dos de origem natural. Vittalle, v. 1, n. 19, p. 35-44, 2007.

RADU, B. M. et al. Neurovascular unit in chronic pain. Mediators inflammatory, v. 2013, n. 648268, p. 1-18, 2013.

RANG, H. P.; DALE, M. M.; RITTER, J. M.; FLOWER, R. J.; HENDERSON, G. Farmacologia. 7 ed. Rio de Janeiro: Elsevier. 2012. 808p.

RIGOTTI, M. A.; FERREIRA, A. M. Intervenções de enfermagem ao paciente com dor. Arq. Ciênc. Saúde, v. 12, n. 1, p. 50-54, 2005.

SILVA, M. DE L. C. et al. Caracterização química de glucanas fúngicas e suas aplicações biotecnológicas. Química Nova. v. 29, n. 1, p. 85-92, 2006.

VERMA, P. R.et al. Antinociceptive activity of alcoholic extract of Hemidesmus indicus R. Br. in mice. J Ethnopharmacol, v. 102, p. 298-301, 2005.

ZIRMERMANN, M. Ethical guidelines for investigations of experimental pain in conscious animals. Pain 16, v. 2, p. 109-10. 